\title{
Free Nipple Grafting as A Simple Technique in Severe Forms of Post-Bariatric Male Pseudogynecomastia
}

\author{
IBRAHIM HUSSEIN KAMEL, M.D. \\ The Department of Plastic, Burn \& Maxillofacial Surgery, Faculty of Medicine, Ain Shams University
}

\begin{abstract}
Background: Male breast deformity after massive weight loss represent an embarrassing situation for male.

Material and Methods: This study included 20 patients with massive weight loss after bariatric surgery. They underwent mastectomy and free nipple grafting technique in a simple and quick procedures. Satisfactory aesthetic outcome could be achieved. Minor complications were recorded.

In Conclusion: Free nipple grafting is a straight forward technique that can be applied safely in severe cases with severe forms of pseudogynecomastia after massive weight loss.
\end{abstract}

Key Words: Pseudogynecomastia - Free nipple graft- obesity - Chest contouring.

\section{INTRODUCTION}

The number of obese patients is increasing especially in the last century [1]. The number of patients seeking bariatric surgery is also increasing and subsequently, the male patients presenting for body contouring procedures is growing [2-4].

A common deformity seen in male population is marked skin redundancy of the chest wall which is known as pseudogynecomastia. Pseudogynecomastia is characterized by increased subareolar fat without enlargement of the breast glandular component $[5,6]$. In addition to the aesthetic deformities, patients usually have functional and dermatological disorders [1].

The main problem after massive weight loss is that the overstretched skin does not regress as desired due to loss of its elasticity [7]. Males are very concerned for the appearance of the chest wall and breasts [8]. Removal of excess skin is the usual goal of male breast contouring after massive weight loss. Other goals include reduction of subcutaneous fat with the least possible scarring [1].

This study presents a simple surgical technique of free nipple grafting in the management of male breast redundancy (pseudogynecomastia). The technique is simple, fast, and can address the excess chest wall as well.

\section{PATIENTS AND METHODS}

This study included 20 male patients complaining of pseudogynecomastia after massive weight loss after bariatric surgery. Patients with unilateral gynecomastia and patients receiving anticoagulant or antiplatelet drug therapy were excluded.

History taking included the age, the Body Mass Index (BMI), the amount and rate of weight loss, and weight fluctuation in the last months. Physical examination is performed in upright position. It included breast size, consistency, skin excess, skin elasticity, the diameter of the NippleAreola Complex (NAC), suspicious masses, and nipple areola position in relation to Inframammary Fold (IMF). Physical examination is performed also for the surrounding aesthetic areas (arms and abdomen). Pre-operative ultrasound was done to confirm the presence of glandular tissue and fatty tissues and excludes presence of non-palpable breast masses.

The study was approved by the local scientific committee. The treatment options, alternatives and risks should be explained. The benefits and possible drawbacks were discussed, and informed consent was obtained. 
Surgical marking (Fig. 1): It is performed in standing position. The midline, the breast meridian, NAC position, IMF, breast borders, and degree of breast ptosis are marked. The NAC new position is placed at $14 \mathrm{~cm}$ from the mid-clavicle line. The excess skin in lateral chest wall as well as arms can also be included in the excision area.

Surgical technique: The future IMF is marked then en-block mastectomy with overlying skin is carried on. If there is excess on lateral thoracic wall, the excision is extended through the transverse scar easily up to the axilla. The superior incision line is determined by downward retraction of the chest tissues to the desired location of the final scar. The inferior margin of resection is estimated by pinch test to ensure tension free closure. The entire region is resected, including the chest deformity, lateral chest roll, we start excision from the lower incision in prepectoral plane until second intercostal space. At the end of the procedure, the NAC is grafted $(2.8 \mathrm{~cm}$ in size) and placed at $14 \mathrm{~cm}$ from the mid-clavicle line. This position is usually about $4-5 \mathrm{~cm}$ from the IMF incision line.

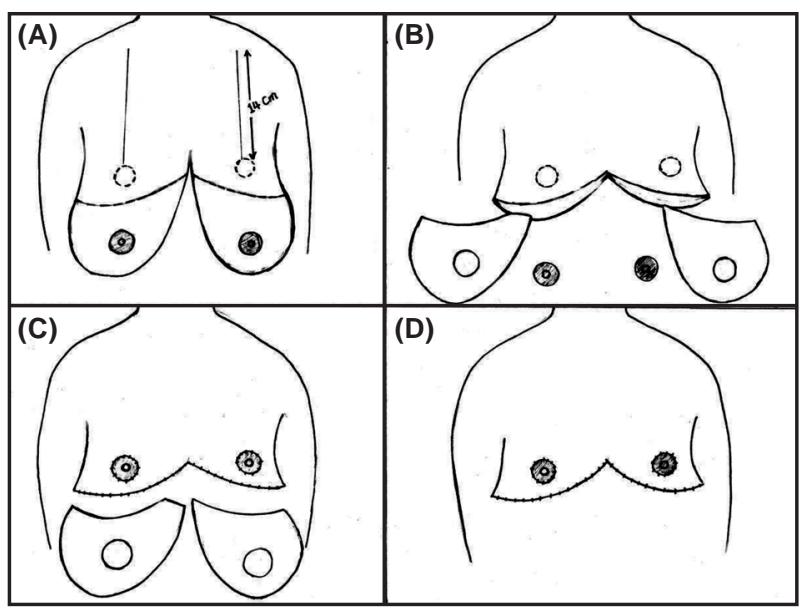

Fig. (1): Simplified diagram of the surgical technique, (A) Marking of the IMF, extent of excision, and future NAC position, (B) Mastectomy and harvesting of NAC free graft, (C) Transverse closure that can be extended to lateral chest wall. (D) Placement of NAC at $14 \mathrm{~cm}$ at mid clavicle line.

A compression garment is applied, and a drain is left in dead space. The compressive garment is used for one month by day and night.

Assessment of results: The degree of aesthetic outcome was evaluated based on surgeon assessment and patient satisfaction. The digital photos were also assessed by an independent physician. The criteria of assessment are adopted from Pacifico and Kang [9] assessment score: Overall breast shape, overall shape in relation to chest wall, nipple areola position and shape, residual skin and/or glandular excess, over-resection, psychosocial relief, and scar quality. Results were graded as excellent (>75\%), good (51-75\%), fair (26-50\%), and poor $(<25 \%)$.

\section{RESULTS}

This study was conducted between 2015 and 2017. Patients age ranged from 22 and 56 years with an average of operated patients was 36.3 years. The average maximum weight achieved by these patients was $122 \mathrm{~kg}(105-153 \mathrm{~kg})$. Average BMI before weight loss was $44.5 \mathrm{~kg} / \mathrm{m}^{2}(38-54 \mathrm{~kg} /$ $\mathrm{m}^{2}$ ). All patients lost weight after bariatric surgery. The average weight loss was $40.2 \mathrm{~kg}$ (ranged between $25-61 \mathrm{~kg}$ ). BMI preoperatively ranged between 24.3 and 36.5 with an average of $28.6 \mathrm{~kg} / \mathrm{m}^{2}$. All patients had an extreme form of pseudogynecomastia ranked as Grade III according to Simon's classification et al., [5] and grade IV according to the classification of Cordova and Moschella [10].

Follow-up period ranged from 6-12 months with an average of 10.4 months.

The resected part ranged from 100-1100g with an average of $550 \mathrm{~g}$ per side. Drains were removed after 3 days and the average hospital stay was about 1-2 days. Patients returned to work after 12 weeks.

Sixteen patients had excellent outcome while four patients reported good outcome Figs. (2-4). No patient had fair or poor results. Satisfactory results could be obtained in overall breast shape and NAC shape and position. There was dramatic improvement of the patient's quality of life after surgical treatment. After surgery, all patients were able to expose their chest and breast in public without embarrassment. On the other hand, all these patients avoided such conditions before surgery. Furthermore, all patients achieved result more than their wishes and they showed that they would repeat choice of surgery again.

The recorded complications were hematoma in 2 patients and partial loss and pigment changes of NAC in one patient Fig. (5). 

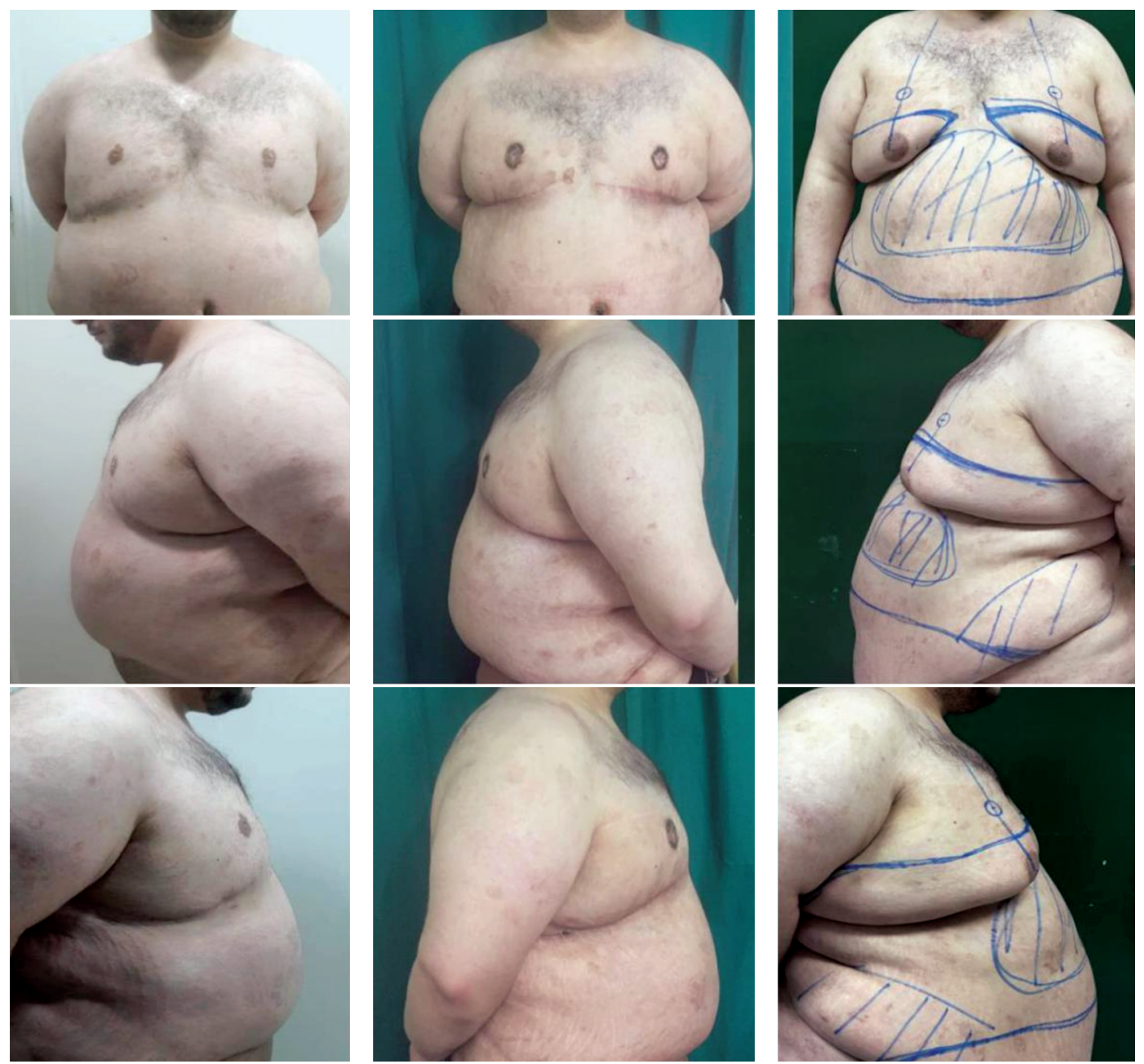

Fig. (2): Pre-operative and post-operative views of a 36 years old patient.
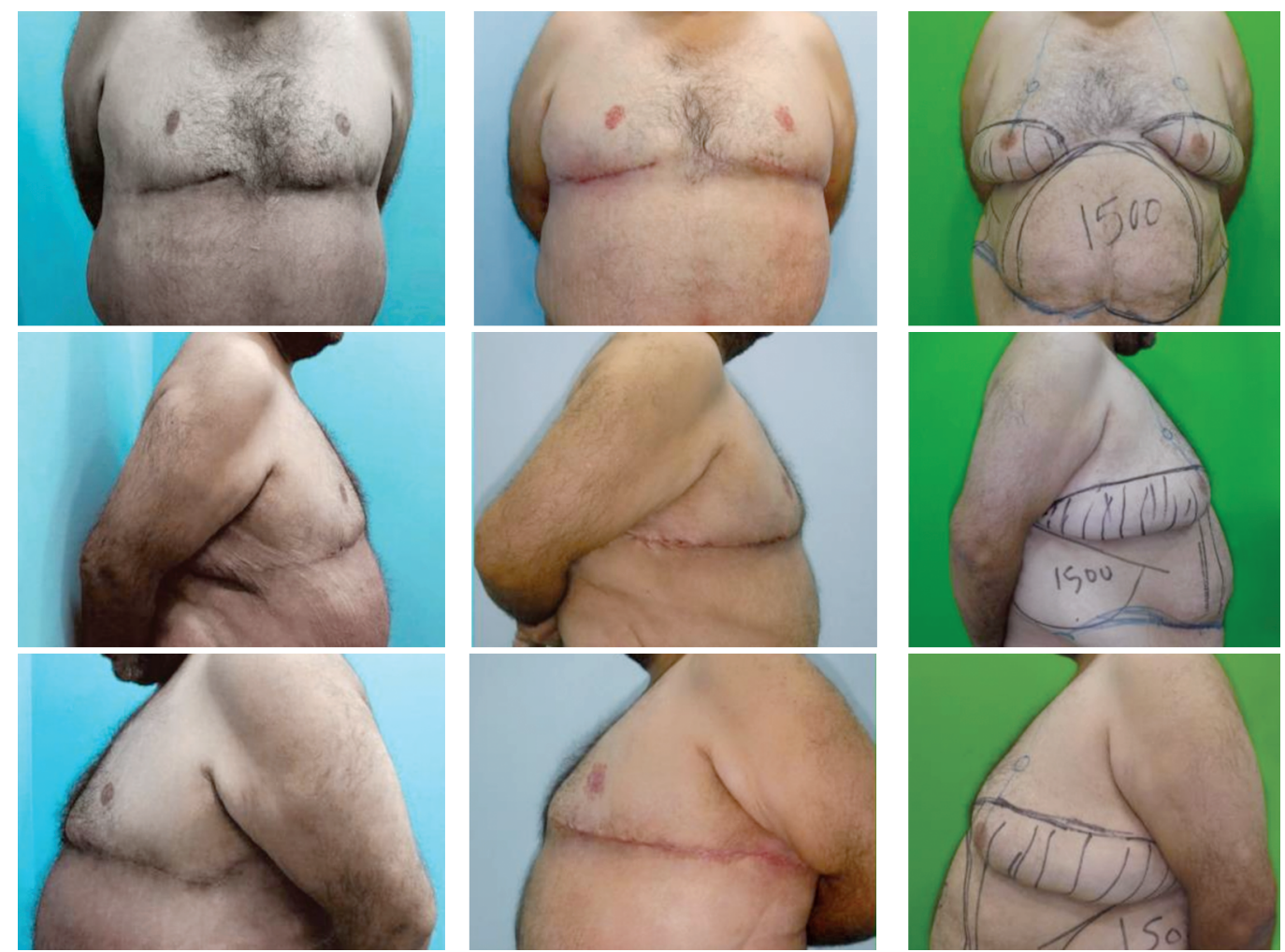

Fig. (3): Pre-operative and post-operative views of a 47 years old patient. 

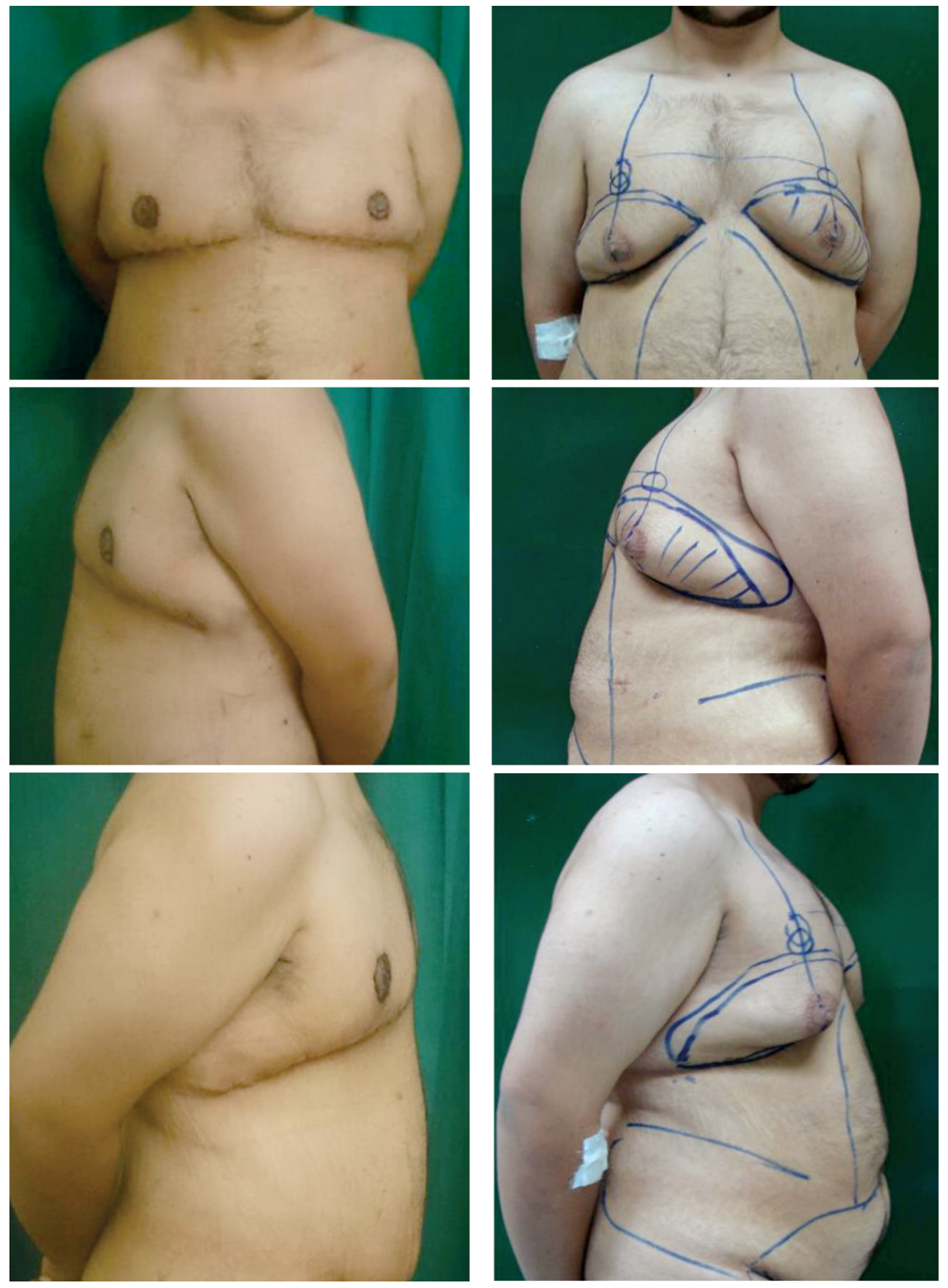

Fig. (4): Pre-operative and post-operative views of a 29 years old patient.

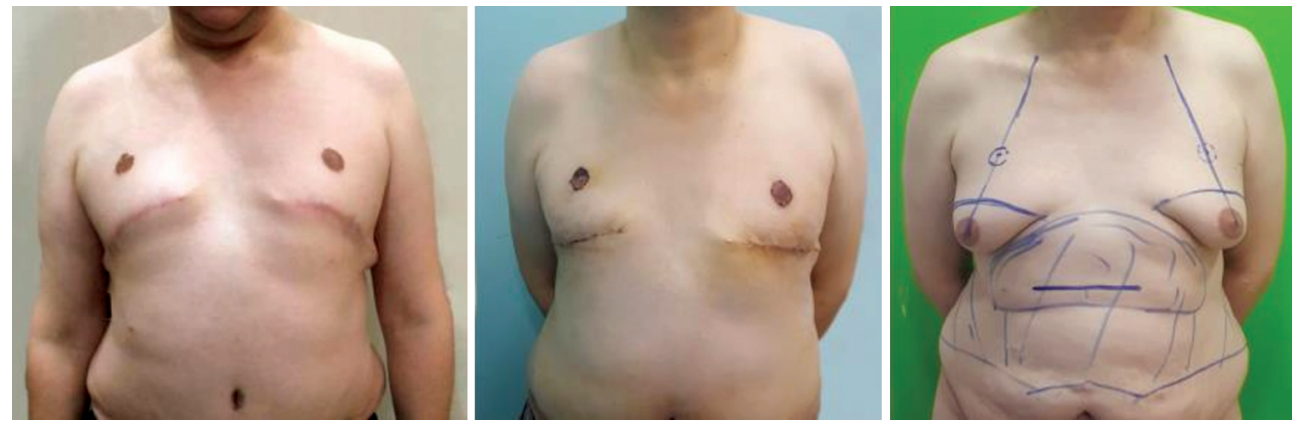

Fig. (5): Partial loss and pigment changes of the right NAC. 


\section{DISCUSSION}

The deformities of the male chest after massive weight loss vary significantly. Many techniques are described for treating gynecomastia, however, results in severe grades of the deformity can be challenging [11-15]. Extensive excision with scarring is usually needed to obtain satisfactory outcome [4].

Theoretically, preservation of the NAC on a pedicle allows for neurovascular function, more natural appearance, and less dyspigmentary changes. However, it can be more time consuming or ultimately end by free graft. Although, free-nipple grafts are initially insensate, may have "stuck-on" appearance, and are prone to pigment changes, it is still a quick and technically simple procedure [4].

The technique of NAC amputation and grafting was first described by Thorek [16] in 1922 for female gigantomastia. Then, Campos [17] described the free NAC grafting in extreme gynecomastia patients. The resultant scar was mediothoracic with grafted nipple placed on the scar. Later, Wray and colleges [18] refined the technique and proposed to place the scars to be at base of thorax. All these techniques lack the effectiveness for management of residual cutaneous excesses at lateral thoracic wall [19].

The position of the nipple-areola complex in relation to the inframammary fold in men is an important concept but has not received much consideration when determining the location of the male nipple-areola complex on the chest wall $[20,21]$.

Gusenoff et al., [4] compared the pedicled reconstruction technique to free-nipple technique. they found that all patients stated that they would undergo the surgery again. The advantages of the pedicled technique over free grafts include a greater chance of preserving sensation, limiting the amount of pigmentation change, and reducing the stuckon appearance. However, it had higher rate of dysesthesias. Interestingly, Gusenoff et al., found that the patients who had free-nipple grafts reported touch sensation in the NAC.

In our work ,the technique allows for satisfactory results as the technique is straight forword and permits excision of desired amount of excess tissue.

The position of NAC is very important to obtain satisfactory results. Atiyeh et al., [22] and Gusenoff and Co-workers [4] studied this issue in detail. In our technique, we tried to simplify this issue to add more facility to the technique. The NAC is placed at $14 \mathrm{~cm}$ from mid-clavicle line and about $4-5 \mathrm{~cm}$ from the transverse chest wall scar. This proposed position is comparable to the other proposed methods. Therefore, after our initial cases, we used this simple method for NAC positioning.

\section{Conclusion:}

Free nipple grafting and total male breast tissue excision is a simple and effective technique in the management of severe breast skin redundancy in post-bariatric surgery. Chest wall deformity can also be managed concomitantly and effectively. NAC position at the proposed distances achieve very satisfactory results.

\section{REFERENCES}

1- Stoff A., Reichenberger M.A. and Richter D.F.: Male breast contouring after massive weight loss Handchir. Mikrochir. Plast. Chir., Aug., 38 (4): 209-16, 2006.

2- Aly A.: Body Contouring After Massive Weight Loss. St. Louis: Quality Medical Publishing, 2005.

3- Aly A., Pace D. and Cram A.: Brachioplasty in the patient with massive weight loss. Aesthetic. Surg. J., 26: 76-84, 2006.

4- Gusenoff J.A., Coon D. and Rubin J.P.: Pseudogynecomastia after Massive Weight Loss: Detectability of Technique, Patient Satisfaction, and Classification. Plast. Reconstr. Surg., Nov., 122 (5): 1301-11. Doi: 10.1097/ PRS.0b013e3181881df4, 2008.

5- Simon B.E., Hoffman S. and Kahn S.: Classification of gynecomastia. Plast. Reconstr. Surg., 51: 48, 1973.

6- Rohrich R., Ha R., Kenkel J. and Adams W.P. Jr.: Classifications and management of gynecomastia: Defining the role of ultrasound-assisted liposuction. Plast. Reconstr. Surg., 111: 909, 2003.

7- Matarasso A.: The male abdominoplasty. Clin. Plast. Surg., 31: 555-569, V-VI, 2004.

8- Brenner P., Berger A., Schneider W. and Axmann H.D.: Male reduction mammoplasty in serious gynecomastias. Aesthetic. Plast. Surg., 16: 325-330, 1992.

9- Pacifico M.D. and Kang N.V.: The tuberous breast revisited. J. Plast. Reconstr. Aesthet. Surg., 60 (5): 455-64, 2007.

10- Cordova A. and Moschella F.: Algorithm for clinical evaluation and surgical treatment of gynaecomastia. J. Plast. Reconstr. Aesthet. Surg., 61 (1): 41-9 [Epub 2007 Nov 5 Review], 2008.

11- Hodgson E.L., Fruhstorfer B.H. and Malata C.M.: Ultrasonic liposuction in the treatment of gynecomastia. Plast. Reconstr. Surg., 116: 646, 2005.

12- Tashkandi M., Al-Qattan M.M., Hassanain J.M., Hawary M.B. and Sultan M.: The surgical management of highgrade gynecomastia. Ann. Plast. Surg. 53: 17, 2004. 
13- Kornstein A.N. and Cinelli P.B.: Inferior pedicle reduction technique for larger forms of gynecomastia. Aesthetic. Plast. Surg., 16: 331, 1992.

14- Persichetti P., Berloco M., Casadei R.M., Marangi G.F., Di Lella F. and Nobili A.M.: Gynecomastia and the complete circumareolar approach in the surgical management of skin redundancy. Plast. Reconstr. Surg., 107: 948, 2001.

15- Song A.Y., Jean R.D., Hurwitz D.J., Fernstrom M.H., Scott J.A. and Rubin J.P.: A classification of contour deformities after bariatric weight loss: The Pittsburgh rating scale. Plast. Reconstr. Surg., 116: 1535, 2005.

16- Thorek M.: Possibilities in the reconstruction of the human form 1922. Aesthetic. Plast. Surg., 13 (1): 55-8, 1989.

17- Campos F.: Sobre um caso de ginacomastia, bilateral e seu tratamento cirurgico. Arquivos de Cirurgia Clinica e Experimental., 6: 703-5, 1942.

18- Wray Jr. R.C., Hoopes J.E. and Davis G.M.: Correction of extreme gynaecomastia. Br. J. Plast. Surg., 27 (1): 3941, 1974.

19- Maetz B., Bodin F., Abbou R., Wilk A. and Bruant-Rodier C.: Management of weight loss sequelae in the man chest: The amputation grafting technique with a L scar. Ann. Chir. Plast. Esthet., Dec., 58 (6): 650-7. Doi: 10.1016/ j.anplas.2012.07.015, 2013.

20- Beer G.M., Budi S., Seifert B., Morgenthaler W., Infanger M. and Meyer V.E.: Configuration and localization of the nipple-areola complex in men. Plast. Reconstr. Surg., 108: 1947, 2001.

21- Shulman O., Badani E., Wolf Y. and Hauben D.J.: Appropriate location of the nipple-areola complex in males. Plast. Reconstr. Surg., 108: 348, 2001.

22- Atiyeh B.S., Dibo S.A. and El-Chafic A.H.: Vertical and Horizontal Coordinates of the Nipple-Areola Complex Position in Males. Ann. Plast. Surg., Nov., 63 (5): 499502. doi: 10.1097/SAP.0b013e3181953854, 2009. 